\title{
Genomic study of oral lichen planus and oral microbiome with RNAseq
}

Evelyn F. Zhong*, Andrea Chang, Andres Stucky, Xuelian Chen, Tarun Mundluru, Mohammad Khalifeh, and Parish P. Sedghizadeh*

Division of Periodontology, Diagnostic Sciences \& Dental Hygiene, Herman Ostrow School of Dentistry, University of Southern California, Los Angeles, CA, 90089, USA

\section{Corresponding authors:}

*Evelyn F. Zhong: ez_405@usc.edu

*Parish P. Sedghizadeh: sedghiza@usc.edu 


\begin{abstract}
Oral lichen planus (OLP) is a common chronic inflammatory disease affecting the oral mucosa. The pathogenesis of OLP is incompletely understood but is thought to be related to the immune system. As the oral cavity is a major reservoir and transmission gateway for bacteria, viruses, and fungi, the microbial composition of the oral cavity could play a role in the pathogenesis of OLP. However, due to limitations of analytic technology and incomplete knowledge of the microbial community in the oral cavity, it is not yet clear which pathogens are associated with OLP. Next-generation sequencing (NGS) is a powerful tool that can help to identify pathogens for many infectious diseases. In this study, we compared host cell gene expression profiles and microbial profiles from OLP patients and matched healthy individuals. We identified activation of the hepatocyte nuclear factor alpha (HNF4A) network in OLP patients and potential pathogens, including Corynebacterium matruchotii, Fusobacterium periodonticum, Streptococcus intermedius, Streptococcus oralis, and Prevotella denticola. P. denticola is capable of activating the HNF4A gene network. Our findings shed light on the previously elusive association of OLP with various diseases like hepatitis, and indicate that OLP is a T-helper type 17 (Th17)-mediated mucosal inflammatory process. The molecular pathways and microbes identified here can inform future investigations into OLP pathogenesis and development of novel therapeutics for OLP treatment.
\end{abstract}

Keywords: T-helper cell, RNAseq, microbiome, HNF4A, Prevotella denticola, lichen planus pathogenesis 


\section{INTRODUCTION}

Lichen planus is a common chronic mucocutaneous inflammatory disease affecting the skin, nails, eyes, urogenital tract, and oral mucosa. (1) Oral lichen planus (OLP) occurs specifically in the oral cavity. It is believed to affect the oral mucosa through T-cell mediated chronic inflammation, and some investigators have suggested that Th2-mediated inflammation can also contribute to the pathogenesis of OLP. (2)

Five clinical subtypes of OLP are usually seen: reticular, plaque-like, atrophic, erosiveulcerative, and bullous. Symptomatic lesions can appear and regress over time. Cutaneous involvement in addition to oral mucosal lesions is seen clinically in a subset of patients. (3) The most commonly affected oral location affected, regardless of subtype, is the buccal mucosa, usually with symmetrical involvement.(4) This is followed by the gingiva, tongue, lip, and palate. OLP has a greater prevalence in females compared to males, and in females typically takes a more chronic course and has higher potential for significant morbidity. (5) OLP has a prevalence of approximately $0.5-2 \%$ with an age of onset between 30 and 60 years. (3)

A major clinical challenge for clinicians is providing patients with successful management or treatment of OLP without negative side effects. Currently, one of the most common treatments for OLP is topical corticosteroids. (6) Topical therapy is commonly favored over systemic therapy as the former is easier and more cost-effective than the latter. Systemic therapy often requires additional treatment such as concomitant topical therapy. (7) However, some patients do not respond to topical therapy. Also, the use of topical treatments without proper monitoring and evaluation can lead to oral candidiasis with associated burning mouth and hypogeusia, hypersensitivity reactions to the drug, inhibition of the hypothalamic-pituitaryadrenal axis and secondary adrenal insufficiency, or blood glucose dysregulation. Reports of 
patients with reactions to topical corticosteroids have also been detailed and highlight the challenges in managing patients with OLP. (8).

Investigating the gene networks of host cells and the microbiome associated with OLP could have a significant impact on our understanding and ultimately clinical treatment of OLP. In this study, we performed RNAseq to compare the host gene expression and microbial profiles of OLP patients with those of healthy controls. We identified specific host gene expression profiles of OLP as well as unique microbial profiles in OLP patients. These findings provide insights into OLP pathogenesis and could help inform future targeted therapies.

\section{METHODS}

Patient population: Institutional Review Board approval was obtained for this study (USC IRB \# HS-16-00518). Inclusion criteria for OLP patients included males or females over age 50 with biopsy and histologically confirmed lichen planus diagnosis by a board-certified oral pathologist, and the ability to provide informed consent. Exclusion criteria for OLP patients included xerostomia or significant polypharmacy where saliva collection could be difficult or prohibitive, active systemic infection or oral infection such as periodontitis or abscess, detectable subgingival or supragingival plaque, active antibiotic therapy, and any history of skin involvement with lichen planus. Ascertainment criteria for controls included healthy male or female patients over age 50 without a diagnosis of cutaneous or oral lichen planus in any form, one or no comorbidities, no xerostomia or polypharmacy, no active systemic or oral/periodontal infection, and no detectable subgingival or supragingival plaque.

Sample collection: Saliva and buccal mucosa wash samples of patients diagnosed with OLP $(n=4)$ and healthy controls $(n=4)$ were collected in OMNIgene saliva collection kits (Genotek). Saliva and buccal wash cells were collected from each patient under standardized conditions. 
Salivary flow rates vary significantly among individuals and in the same individual under different conditions or during different times of the day. Thus patients were instructed not to eat, clean, or rinse their mouth 1 hour before saliva collection, because these activities can affect the microbial environment. Saliva for all study subjects was collected at the same time of day using a draining method with the patient in an upright head position. Whole unstimulated saliva was collected for 5 minutes in a Proflow sialometer (Amityville, NY) or until $0.5 \mathrm{~mL}$ of saliva was collected $(0.1 \mathrm{~mL} / \mathrm{min}$ average $)$. Samples were subsequently used for molecular studies.

RNAseq: Libraries were constructed using Nextera DNA Flex Library Prep Kit (Illumina) and the Ribo-Zero rRNA Removal Kit (NEB). DNA and RNA were sequenced and results were analyzed using Partek Flow. To investigate the relationship between OLP and oral microbial status, we conducted DNA and RNA sequencing of patient saliva with buccal epithelial cells and aligned it to both human and bacterial viral genomes. We performed an observational (clinical paired with genomic patient information) study to identify possible associations. For differential expression analysis, we used Partek's Gene Specific Analysis method. To identify significantly differentially expressed genes among different tissues from the same patient, a cutoff of FDR adjusted two-fold change was applied.

Microbial profiling: Centrifuge is a taxonomic profiling tool (9) and was used to allocate unmapped reads to the microbial genomes and calculate the abundance of known microbial organisms for all samples. We used the -q flag to indicate that the input was in fastq format and all other arguments were set to their default values. All the available reference genomes in NCBI for bacterial and viral sequences were used for classification (up to January 4, 2018).

PCR confirmation: PCR assays were used to confirm microbes identified from RNAseq. Primer for detection of Prevotella denticola was: 
Forward Primers: TAATACCGAATGTGCTCATTTACAT

Reversed primer: TCAAAGAAGCATTCCCTCTTCTTCTTA

with an amplicon size of $316 \mathrm{bp}(10)$.

\section{RESULTS}

\section{Clinical and pathologic features}

We studied 10 patients with OLP and five control patients without OLP; our OLP patient population had signs of both reticular and erosive patterns, and the most common sites of involvement were the buccal mucosa, gingiva, and tongue (Table 1). A common clinical sign of OLP is oral lesions with radiating whitish gray lines or thread-like papules sometimes known as Wickham's striae, which can be lacy or reticular, annular, patches, or strings. Desquamative gingivitis is another common finding with OLP (Fig. 1 A\&B). When Wickham's striae predominate clinically, the term 'reticular OLP' is used. When atrophic or ulcerative lesions predominate clinically, the term 'erosive OLP' is used. Significant clinical characteristics of OLP often include lesions that alternate between periods of exacerbation and quiescence, as was seen in our patient population. (11) Patients may notice an irritation to the oral cavity and later develop a burning sensation. The burning sensation can be further aggravated by the intake of spicy or hot foods and can interfere with patient eating habits and quality of life. (12) None of our OLP patients had skin involvement or other tissue involvement outside the oral cavity.

It is usually recommended to confirm the diagnosis of OLP with an oral biopsy and histopathological examination, as lesions may mimic dysplasia or malignancy in addition to other conditions. (13) Thus, we confirmed OLP diagnosis in all studied patients via histopathologic evaluation. Histopathologic criteria for diagnosis include the presence of a welldefined, band-like zone of inflammatory cell or lymphocytic infiltration within the superficial 
part of the connective tissue or lamina propria (Fig. 1C). Histologic evidence of hydropic degeneration in the basal cell layer with absence of epithelial dysplasia is also common. (14) The finding of "saw-tooth"-shaped rete ridges and colloid bodies are other useful features which help support the diagnosis of OLP.

\section{Molecular analysis of OLP-related gene network}

The pathology of OLP is strongly related to immune dysregulation, like any other autoimmune disease. The most popular theory is that activated cytotoxic CD8+ cells target basal keratinocytes, after which CD4+ helper T cells secrete TH1 cytokines. (15) Along with T cells, growth factors, inflammatory and proapoptotic mediators mediate the inflammation. (16) However, as of now, there is no definitive etiology for OLP, though some evidence suggests viral or bacterial infections, local trauma or irritation, systemic disorders, and even excessive alcohol and tobacco consumption are probable factors. (17)

Most of the current evidence supports the notion that OLP is related to immune dysregulation. However, the immune system is not only affected by drugs, systematic metabolic diseases, physical and mental stress, but also by microbiota and pathogens. The oral cavity is the beginning of the gastrointestinal system, and the gut-body connection and microbiome play important roles in maintaining health versus disease in the oral cavity and beyond. Therefore, OLP is likely a result of multiple factors which stress or dysregulate the immune system. By analyzing the gene expression profiles of cells in the oral cavity, we identified 953 genes that showed significantly different expression profiles in lichen planus patients compared to healthy controls. Among the differentially expressed genes, we identified 498 up-regulated and 455 down-regulated genes $(\mathrm{p}<0.05$, fold change $>2)$ between OLP patients and healthy controls

(Fig. 2A). To analyze the potential roles of the 953 differentially expressed genes, we used 
Ingenuity Pathway Analysis $\left(\operatorname{IPA}^{\circledR}\right)$ to identify the most likely molecular signaling mechanisms that could account for some of the symptomatic manifestations of OLP. Among the OLP patients, specifically enriched signaling pathways identified several genes coding for proteins involved in nicotine degradation $(\mathrm{p}=0.003)$, cysteine biosynthesis and homocysteine degradation $(\mathrm{p}=0.015)$, as well pathways associated with increased activation of hepatocyte nuclear factor alpha (HNF4A) $(\mathrm{p}=0.015)$ and the modulation of its various downstream signaling molecules (Fig 2B). HNF4A is highly expressed in lymphatic tissue and in the salivary glands, which is consistent with the observation of an activated HNF4A gene network. Among the genes in this network, the largest difference in expression was observed in the sterol O-acyltransferase 2 gene (SOAT2) (increased 9-fold; $\mathrm{p}=0.005$ ), a protein involved in cholesterol metabolism that has been implicated in various types of cancer including epithelial and liver cancer as well as hepatocellular carcinoma, melanoma, and acute myeloid leukemia. In addition to SOAT2, CYP2C8 was upregulated (2-fold; $p=0.03$ ) and is an unspecific monoxygenase. Selectin $\mathrm{P}$ $(S E L P)$ was also upregulated (2-fold; $\mathrm{p}=0.004)$ and is a cell adhesion protein upregulated in response to bacterial infections, delayed hypersensitivity reaction, T-cell lymphoma, and systemic lupus erythematosus.

\section{Microbes associated with OLP}

Considering that a typical oral cavity contains more than 500 different bacterial species and various viruses and yeast (18), the oral microbiome may play a significant and as-yetundetermined role in OLP etiopathogenesis. Current next-generation sequencing (NGS) techniques provide powerful tools that can be used to identify the potential pathogens of OLP and facilitate new potential therapies. In particular, RNAseq can simultaneously identify microbial and host gene expression. As a proof of concept, we performed molecular analysis 
using RNAseq to compare OLP patients to healthy controls (Table 1) and we were able to identify putative candidates for OLP pathogenesis (Fig 3). Of the identified microorganisms, 25 bacterial species were observed to be differentially expressed between OLP patients and healthy controls. A higher prevalence of Corynebacterium matruchotii, Fusobacterium periodonticum, Streptococcus intermedius, Streptococcus oralis and Prevotella denticola was found in patients with OLP as compared to controls (Fig 4). Clinically, these pathogens are significant, and in the context of OLP it has been established that patients with poor oral hygiene and plaque containing periodontopathogens respond poorly to conventional treatments for their OLP until their hygiene and plaque are adequately controlled. We also utilized PCR to confirm that C. matruchotii, F. periodonticum, $S$. intermedius, $S$. oralis, and $P$. denticola are dominant bacteria in OLP patients versus controls (Fig 4). Finally, we also identified a higher abundance of viruses in OLP patients than in healthy controls. Three viral species were statistically significantly higher in OLP patients than in controls (Fig 5), namely tick-borne encephalitis virus, bacillus virus SPO1, and a brochothrix bacteriophage virus.

\section{DISCUSSION}

Since the causes of OLP have not been fully determined, there is no definitive cure for the condition. The first-line drugs in the treatment of OLP are topical corticosteroids due to their ability to modulate inflammation and immune responses by reducing the lymphocytic exudate and stabilizing the lysosomal membrane. (19) If topical steroids are not able to provide clinical relief and resolution or remission of painful erosive lesions, then systemic corticosteroids may be administered. $(20,21)$ Immune suppressants such as cyclosporine, a calcineurin inhibitor, are also used to reduce symptoms of inflammation and irritation.(20) Calcineurin is a protein phosphatase which is involved in the activation of transcription of IL-2 and stimulates the growth 
and differentiation of the T-cell response. By using calcineurin inhibitors, inflammation driven by T-cells, a suspected catalyst in the development of OLP, can be stopped. (19)

However, because knowledge of the underlying mechanism of OLP is lacking, current therapies are mainly prescribed based on their empirical results. In immunosuppressive therapy, topical calcineurin inhibitors (TCI) including tacrolimus, pimecrolimus, and cyclosporine are still controversial for use in this setting. Side effects include oral candidiasis, bad taste, nausea, dry mouth, sore throat, and swollen mouth but are considered minimal.(22) Topical retinoids such as tretinoin, isotretinoin, fenretinide, and tezarotene are generally less effective than topical corticosteroids and are more likely to cause adverse side effects.(23) When considering topical retinoids for treatment, the positive effects should be weighed against their rather significant side effects like cheilitis, elevation of serum liver enzymes and triglyceride levels, and teratogenicity. (19) Biologics and disease-modifying anti-rheumatic drugs (DMARDs) are also used in this setting, usually for cases that do not respond to steroid therapy.

It is critical to identify molecular pathways active in saliva and oral cavity cells of OLP patients and the related pathogens in order to improve OLP treatment and achieve resolution. Here, we found activation of the HNF4A gene network in oral cavity cells of OLP patients (Fig 6), and we further identified several periodontopathogens, including Prevotella denticola, which dominated in patients with OLP. Hepatocyte nuclear factor-4-alpha (HNF4A) is a member of the nuclear receptor superfamily of ligand-dependent transcription factors(24) and is the most abundant DNA-binding protein in the liver, where it regulates genes largely involved in the hepatic gluconeogenic program and lipid metabolism.(25) Besides the liver and pancreas (26), it is highly expressed in the kidney where it is involved with drug metabolism, (27) and also in the small intestine and colon where it is involved in inflammation. $(28,29)$ HNF4A is also known to 
affect inflammation and immune pathways in other immune-mediated conditions like Crohn's disease (30) and inflammatory bowel syndrome.(28)

The HNF4A network could explain previously elusive associations of OLP with various diseases. Previously, chronic liver disease and hepatitis $\mathrm{C}$ have been found to be associated with OLP along with the presence of HLA-DR 6 (31) and HLA-A3. (32) Conditions like hypertension and diabetes mellitus also tend to have comorbidity with lichen planus.(20,33) These associations may be due to disease effects on the HNF4A gene network in modulating the inflammatory and immune pathways of cells in the oral cavity. HNF4A network activation also explains the association of OLP or OLP-like (lichenoid) reactions with specific pharmacotherapies including beta blockers, nonsteroidal anti-inflammatory drugs, anti-malarials, diuretics, oral hypoglycemics, penicillamine, and oral retroviral medications. (20) These interesting associations of drug intake with OLP may be due to the systematic alteration of the HNF4A gene network and in the liver and kidney where it is involved in drug metabolism. (27) We also identified a potential major pathogen, $P$. denticola, which could activate the HNF4A network in cells of the oral cavity. P. denticola may serve as a target for future therapies in this context, though further and larger studies will be needed to more reliably assess and validate this association. Prevotella species are found in humans as opportunistic pathogens. (34) More than twenty identified species of Prevotella are known to cause infection. (35) P. denticola has been isolated from the human mouth, where it is suspected to cause disease, (36) but its pathogenesis in OLP has remained elusive until this study. It has been reported that increased Prevotella abundance is associated with augmented T-helper type 17 (Th17)-mediated mucosal inflammation.(37) It has also been reported that HNF4A mutation is associated with Th17 cellmediated inflammation of the gut mucosa. $(38,39)$ Taken together, our findings support the 
hypothesis that $P$. denticola abundance in the oral cavity can lead to activation of the HNF4A gene network in cells, resulting in Th17-mediated mucosal inflammation and diseases like OLP. We also found greater viral abundance in OLP patients compared to healthy controls. Interestingly, OLP can have a clinical course similar to viral diseases affecting the oral cavity: specifically, the waxing and waning nature of the disease with bouts of active lesions and symptoms, followed by periods of quiescence or remission. Additionally, bacterial and viral interactions are key to many pathologic conditions, including those that involve the oral cavity. Certain bacteria have been shown to increase lytic replication of oral herpesvirus pathogens and thus polymicrobial interactions are likely key to disease pathogenesis. We have previously characterized a significant number of bacteriophage viruses in oral infectious diseases such as osteomyelitis and osteonecrosis, and such profiles were more abundant in diseased patients than in healthy controls.(40) Although the present work represents a preliminary small-scale study, we found a higher abundance of bacteriophages in OLP patients compared to controls. These findings taken together suggest that bacterial and viral interactions are important to oral disease processes that have inflammatory components, and OLP may be another such disease modulated by complex microbial and host interactions. 


\section{References}

1. Baek K, Choi Y. 2018. The microbiology of oral lichen planus: Is microbial infection the cause of oral lichen planus? 33:22-28.

2. Di Stasio D, Guida A, Salerno C, Contaldo M, Esposito V, Laino L, Serpico R, Lucchese A. 2014. Oral lichen planus: a narrative review. Front Biosci (Elite Ed) 6:370-6.

3. Axell T, Rundquist L. 1987. Oral lichen planus--a demographic study. Community Dent Oral Epidemiol 15:52-6.

4. Bonar-Alvarez P, Perez Sayans M, Garcia-Garcia A, Chamorro-Petronacci C, Gandara-Vila P, Luces-Gonzalez R, Otero Rey E, Blanco-Carrion A, Suarez-Penaranda JM. 2019. Correlation between clinical and pathological features of oral lichen planus: A retrospective observational study. Medicine (Baltimore) 98:e14614.

5. Olson MA, Rogers RS, 3rd, Bruce AJ. 2016. Oral lichen planus. Clin Dermatol 34:495-504.

6. George S, Balan A. 2018. A potential side effect of oral topical steroids: Central serous chorioretinopathy. Indian J Dent Res 29:107-108.

7. Carbone M, Goss E, Carrozzo M, Castellano S, Conrotto D, Broccoletti R, Gandolfo S. 2003. Systemic and topical corticosteroid treatment of oral lichen planus: a comparative study with long-term follow-up. J Oral Pathol Med 32:323-9.

8. Bakshi SS. 2017. A burning sensation in the mouth. Cleve Clin J Med 84:344-345.

9. Kim D, Song L, Breitwieser FP, Salzberg SL. 2016. Centrifuge: rapid and sensitive classification of metagenomic sequences. Genome Res 26:1721-1729.

10. Kim J-H, Yoo SY, Lim S-A, Kook J-K, Lim S-S, Park S-H, Hwang H-K. 2003. Identification of putative pathogens in acute endodontic infections by PCR based on 16S rDNA. J Korean Acad Conserv Dent 28:178-183.

11. Krupaa RJ, Sankari SL, Masthan KMK, Rajesh E. 2015. Oral lichen planus: An overview. Journal of pharmacy \& bioallied sciences 7:S158-S161.

12. Hasan S. 2019. Lichen planus of lip - Report of a rare case with review of literature. J Family Med Prim Care 8:1269-1275.

13. Ismail SB, Kumar SK, Zain RB. 2007. Oral lichen planus and lichenoid reactions: etiopathogenesis, diagnosis, management and malignant transformation. J Oral Sci 49:89-106.

14. van der Meij EH, van der Waal I. 2003. Lack of clinicopathologic correlation in the diagnosis of oral lichen planus based on the presently available diagnostic criteria and suggestions for modifications. J Oral Pathol Med 32:507-12.

15. Lehman JS, Tollefson MM, Gibson LE. 2009. Lichen planus. International Journal of Dermatology 48:682-694.

16. Tziotzios C, Lee JYW, Brier T, Saito R, Hsu CK, Bhargava K, Stefanato CM, Fenton DA, McGrath JA. 2018. Lichen planus and lichenoid dermatoses: Clinical overview and molecular basis. J Am Acad Dermatol 79:789-804.

17. Salehi B, Jornet PL. 2019. Plant-Derived Bioactives in Oral Mucosal Lesions: A Key Emphasis to Curcumin, Lycopene, Chamomile, Aloe vera, Green Tea and Coffee Properties. 9.

18. Moore WE, Moore LV. 1994. The bacteria of periodontal diseases. Periodontol 2000 5:66-77.

19. Lavanya N, Jayanthi P, Rao UK, Ranganathan K. 2011. Oral lichen planus: An update on pathogenesis and treatment. J Oral Maxillofac Pathol 15:127-32.

20. Krupaa RJ, Sankari SL, Masthan KM, Rajesh E. 2015. Oral lichen planus: An overview. J Pharm Bioallied Sci 7:S158-61.

21. Alrashdan MS, Cirillo N, McCullough M. 2016. Oral lichen planus: a literature review and update. Arch Dermatol Res 308:539-51. 
22. Thongprasom K, Dhanuthai K. 2008. Steriods in the treatment of lichen planus: a review. J Oral Sci 50:377-85.

23. Carrozzo M, Porter S, Mercadante V, Fedele S. 2019. Oral lichen planus: A disease or a spectrum of tissue reactions? Types, causes, diagnostic algorhythms, prognosis, management strategies. Periodontol 2000 80:105-125.

24. Evans RM, Mangelsdorf DJ. 2014. Nuclear Receptors, RXR, and the Big Bang. Cell 157:255-66.

25. Chandra V, Huang P, Potluri N, Wu D, Kim Y, Rastinejad F. 2013. Multidomain integration in the structure of the HNF-4alpha nuclear receptor complex. Nature 495:394-8.

26. Huang J, Levitsky LL, Rhoads DB. 2009. Novel P2 promoter-derived HNF4alpha isoforms with different N-terminus generated by alternate exon insertion. Exp Cell Res 315:1200-11.

27. Martovetsky G, Tee JB, Nigam SK. 2013. Hepatocyte nuclear factors 4alpha and 1alpha regulate kidney developmental expression of drug-metabolizing enzymes and drug transporters. Mol Pharmacol 84:808-23.

28. Chahar S, Gandhi V, Yu S, Desai K, Cowper-Sal-lari R, Kim Y, Perekatt AO, Kumar N, Thackray JK, Musolf A, Kumar N, Hoffman A, Londono D, Vazquez BN, Serrano L, Shin H, Lupien M, Gao N, Verzi MP. 2014. Chromatin profiling reveals regulatory network shifts and a protective role for hepatocyte nuclear factor 4alpha during colitis. Mol Cell Biol 34:3291-304.

29. Marcil V, Seidman E, Sinnett D, Boudreau F, Gendron FP, Beaulieu JF, Menard D, Precourt LP, Amre D, Levy E. 2010. Modification in oxidative stress, inflammation, and lipoprotein assembly in response to hepatocyte nuclear factor 4alpha knockdown in intestinal epithelial cells. J Biol Chem 285:40448-60.

30. Marcil V, Sinnett D, Seidman E, Boudreau F, Gendron FP, Beaulieu JF, Menard D, Lambert M, Bitton A, Sanchez R, Amre D, Levy E. 2012. Association between genetic variants in the HNF4A gene and childhood-onset Crohn's disease. Genes Immun 13:556-65.

31. Carrozzo M, Brancatello F, Dametto E, Arduino P, Pentenero M, Rendine S, Porter SR, Lodi G, Scully C, Gandolfo S. 2005. Hepatitis C virus-associated oral lichen planus: is the geographical heterogeneity related to HLA-DR6? J Oral Pathol Med 34:204-8.

32. LOWE NJ, CUDWORTH AG, WOODROW JC. 1976. HL-A antigens in lichen planus. British Journal of Dermatology 95:169-171.

33. Harries LW, Locke JM, Shields B, Hanley NA, Hanley KP, Steele A, Njolstad PR, Ellard S, Hattersley AT. 2008. The diabetic phenotype in HNF4A mutation carriers is moderated by the expression of HNF4A isoforms from the P1 promoter during fetal development. Diabetes 57:1745-52.

34. Alauzet C, Marchandin H, Lozniewski A. 2010. New insights into Prevotella diversity and medical microbiology. Future Microbiology 5:1695-1718.

35. Ley RE. 2016. Gut microbiota in 2015: Prevotella in the gut: choose carefully. Nat Rev Gastroenterol Hepatol 13:69-70.

36. Ibrahim M, Subramanian A, Anishetty S. 2017. Comparative pan genome analysis of oral Prevotella species implicated in periodontitis. Funct Integr Genomics 17:513-536.

37. Larsen JM. 2017. The immune response to Prevotella bacteria in chronic inflammatory disease. Immunology 151:363-374.

38. Paul G, Khare V, Gasche C. 2012. Inflamed gut mucosa: downstream of interleukin-10. Eur J Clin Invest 42:95-109.

39. Barrett JC, Lee JC, Lees CW, Prescott NJ, Anderson CA, Phillips A, Wesley E, Parnell K, Zhang H, Drummond H, Nimmo ER, Massey D, Blaszczyk K, Elliott T, Cotterill L, Dallal H, Lobo AJ, Mowat C, Sanderson JD, Jewell DP, Newman WG, Edwards C, Ahmad T, Mansfield JC, Satsangi J, Parkes M, Mathew CG, Donnelly P, Peltonen L, Blackwell JM, Bramon E, Brown MA, Casas JP, Corvin A, Craddock N, Deloukas P, Duncanson A, Jankowski J, Markus HS, Mathew CG, McCarthy MI, Palmer CN, Plomin R, Rautanen A, Sawcer SJ, Samani N, Trembath RC, Viswanathan AC, Wood N, 
Spencer CC, et al. 2009. Genome-wide association study of ulcerative colitis identifies three new susceptibility loci, including the HNF4A region. Nat Genet 41:1330-4.

40. Sedghizadeh PP, Yooseph S, Fadrosh DW, Zeigler-Allen L, Thiagarajan M, Salek H, Farahnik F, Williamson SJ. 2012. Metagenomic investigation of microbes and viruses in patients with jaw osteonecrosis associated with bisphosphonate therapy. Oral Surg Oral Med Oral Pathol Oral Radiol 114:764-70. 


\section{Legend}

Fig 1. Clinical and pathologic features of OLP. A) OLP involving the tongue with characteristic white striae (reticular variant) and red atrophic lesions (erosive variant). B) OLP with inflamed and desquamative gingivitis. C) Histopathology of lichen planus demonstrating the characteristic band-like inflammatory cell infiltrate subjacent to the epithelium with "saw-tooth" rete ridge morphology and hydropic degeneration of basal keratinocytes.

Fig 2. Differentially expressed genes between OLP patients and healthy individuals. A. Volcano plot illustrating differentially expressed genes identified in a comparison of OLP patients and healthy controls. Overall, we identified 953 differentially expressed genes, of which 498 were upregulated and 455 were downregulated in OLP patients compared to controls. Further analysis of the differentially expressed genes identified hepatocyte nuclear factor 4 alpha (HNF4A) as a significant upstream regulator of the identified differentially expressed genes. B. Differential gene expression analysis indicated that the HNF4A gene network is activated in OLP patients. Compared to healthy individuals, HNF4A and its downstream targets, CYO2C8, SOAT2 and SELP, are upregulated in OLP samples, while the inhibitor of HNF4A, NPM1, is down-regulated in OLP patients compared to healthy individuals. Red: up-regulated in OLP, Green: down-regulated in OLP.

Fig 3. Relative abundance of identified bacterial and archaea species sequences in the saliva of patients with OLP and healthy controls. Overall, an average of 18 million classified reads were recovered from the RNA libraries and 2 million from the DNA libraries, with no significant difference in microbial flora diversity between groups. Among all samples, 1575 different bacterial species were identified. Of the identified microorganisms, 25 bacterial species were observed to be differentially expressed between the OLP patients and healthy controls.

Fig 4. PCR confirmation that Corynebacterium matruchotii, Fusobacterium periodonticum, Streptococcus intermedius, Streptococcus oralis and Prevotella denticola are dominant bacteria in OLP patients (OLP: $n=10$, Cont: $n=5$ ). As a representative case, PCR primers designed to amplify a $316 \mathrm{bp}$ fragment of Prevotella denticola demonstrate the presence of this bacteria in two OLP patients but not in matched healthy controls (Inset).

Fig 5. Three viral species are significantly different in abundance between OLP patients and healthy controls. P values are $0.0012,0.0074$, and 0.036 respectively from left to right, and error bars represent s.e.m. Virus counts for the majority of species identified were higher in OLP patients than in controls. 

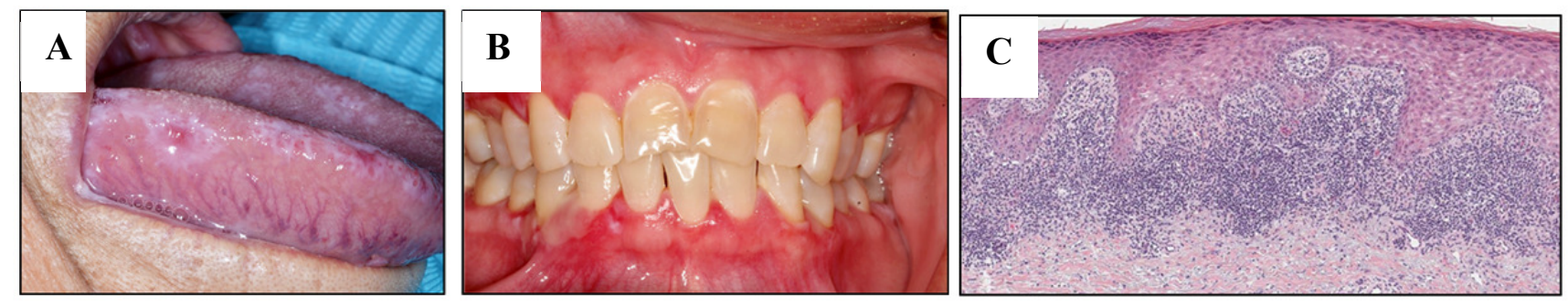

Fig 1. Clinical and pathologic features of OLP. A) image shows OLP involving the tongue with characteristic white striae (reticular variant) and red atrophic lesions (erosive variant). B) image shows OLP with inflamed and desquamative gingivitis. C) Histopathology of lichen planus demonstrates the characteristic band-like inflammatory cell infiltrate subjacent to the epithelium with "saw-tooth" rete ridge morphology and hydropic degeneration of basal keratinocytes. 


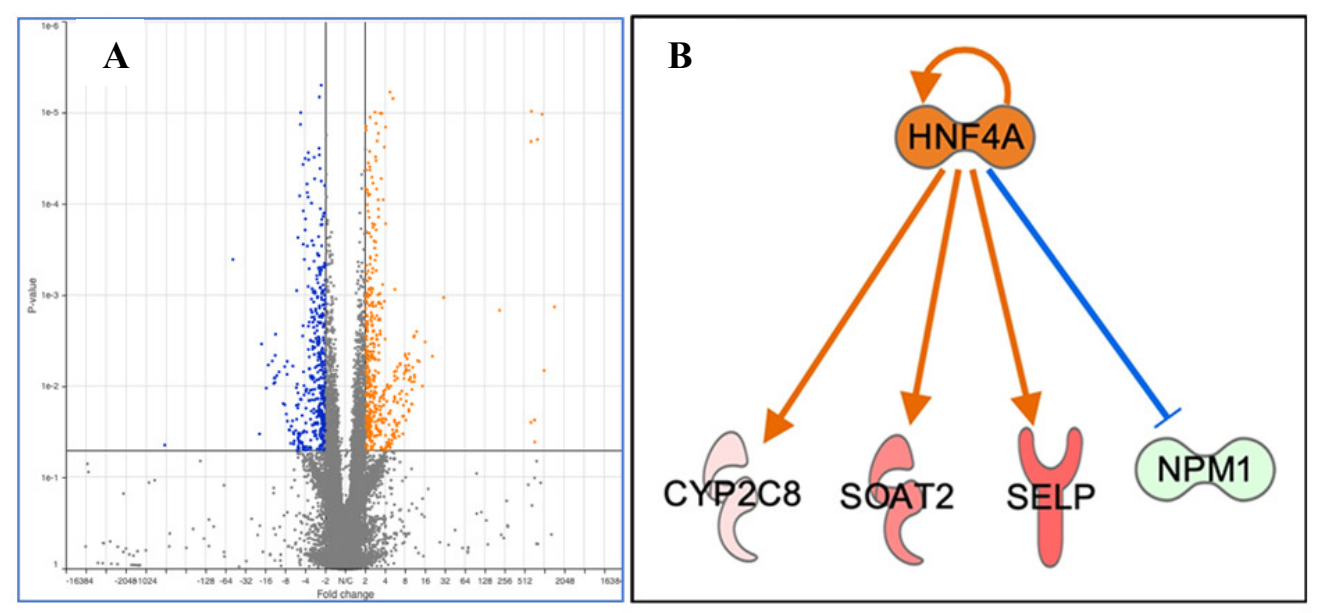

Fig 2. Differential expressed genes between OLP patients and healthy

individuals. A. Volcano plot illustrating differentially expressed genes identified between OLP patients and healthy controls. Overall, we identified 953 differentially expressed genes of which 498 were upregulated and 455 were downregulated between OLP patients and controls. Further analysis of the differentially expressed genes identified hepatocyte nuclear factor 4 alpha (HNF4A) as a significant upstream regulator of the identified differentially expressed genes. B. The hepatocyte nuclear factor alpha (HNF4A) gene network is activated in OLP patients. Differential gene expression analysis indicated that the HNF4A gene network is activated in OLP patients. Comparing to healthy individuals, HNF4A and its down stream targets, CYO2C8, SOAT2 and SELP are upregulated in OLP samples, while the inhibitor of HNF4A, NPM1 is down-regulated in OLP compared to healthy individuals. Red: upregulation in OLP, Green: Down-regulated in OLP. 


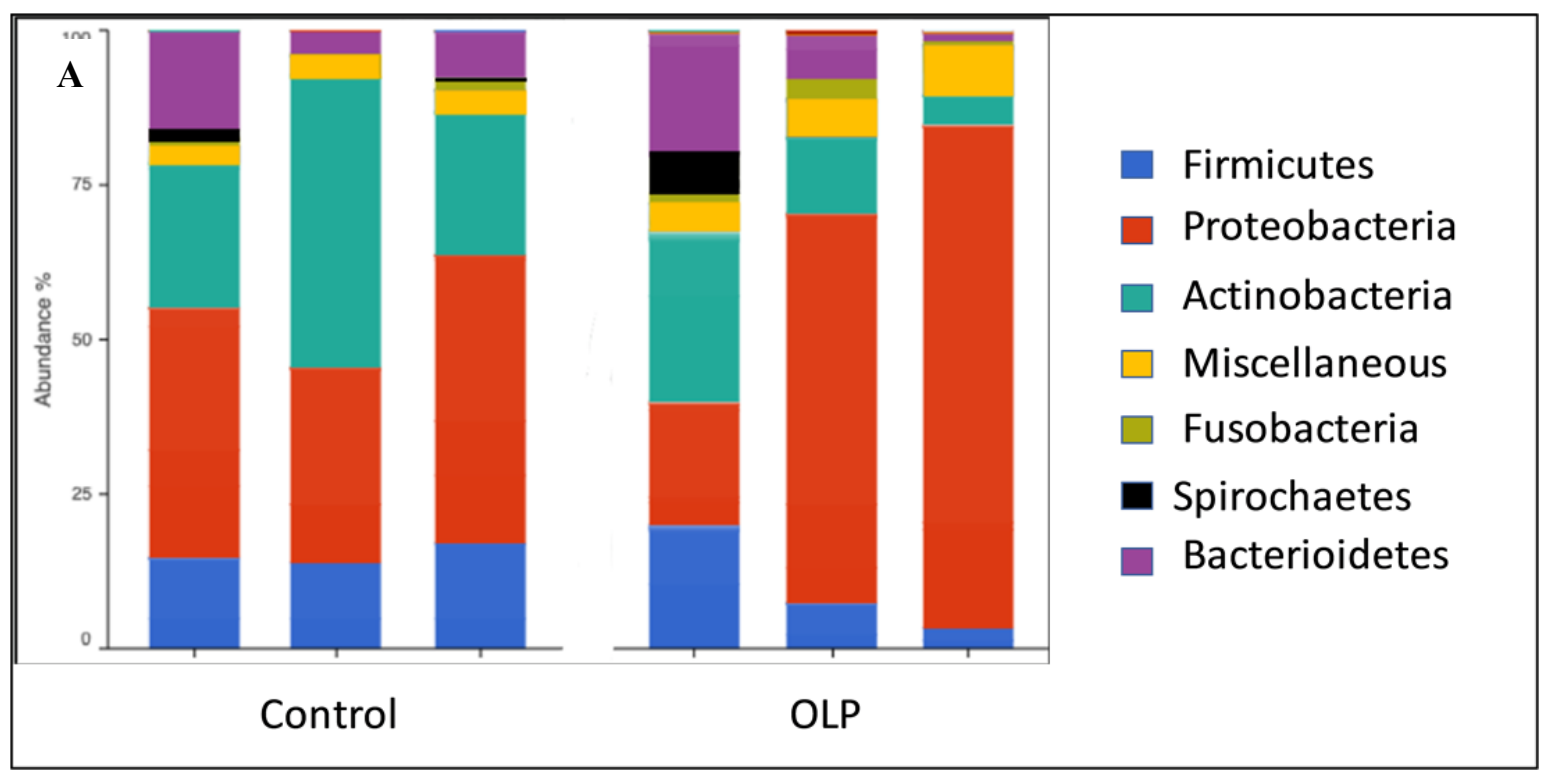

Fig 3. Relative abundance of identified bacterial and archaea species sequences in the saliva of patients with OLP and healthy controls. Overall an average, of 18 Million classified reads were recover from the RNA libraries and 2 million from the DNA, with no significant difference in microbial flora diversity. Among all samples, 1575 different bacterial species were identified. Of the identified microorganisms 25 bacterial species were observed to be differentially expressed between the OLP patients and healthy controls. 


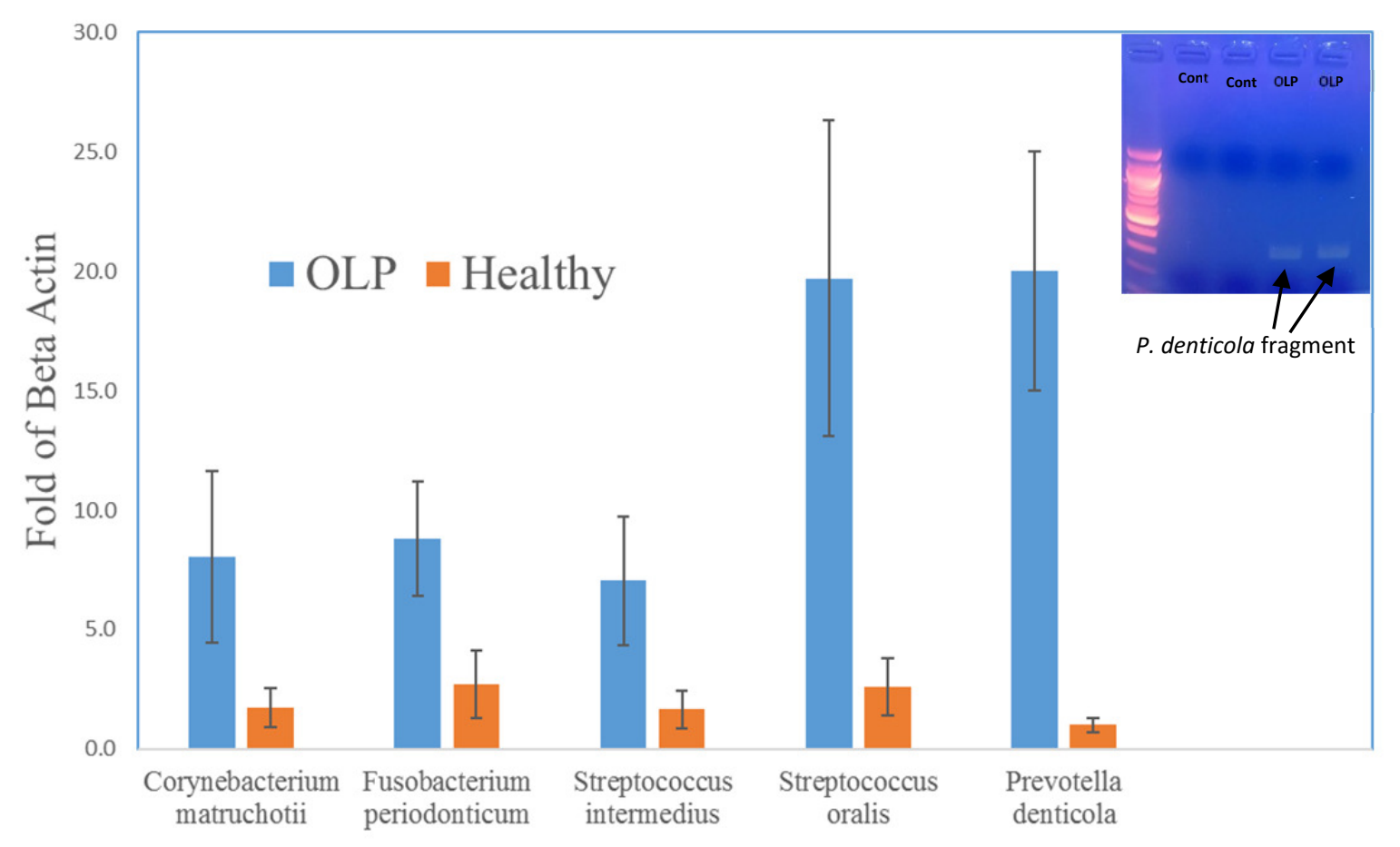

Fig 4. PCR confirmation of Corynebacterium matruchotii, Fusobacterium periodonticum, Streptococcus intermedius, Streptococcus oralis and Prevotella denticola are dominant bacteria in OLP patients (OLP: $n=10$, Cont: $n=5$ ). As a representative case, PCR primers designed to amplify a $316 \mathrm{bp}$ fragment of Prevotella denticola demonstrate the present of this bacteria in two OLP patients but not in matched healthy controls (Inset). 


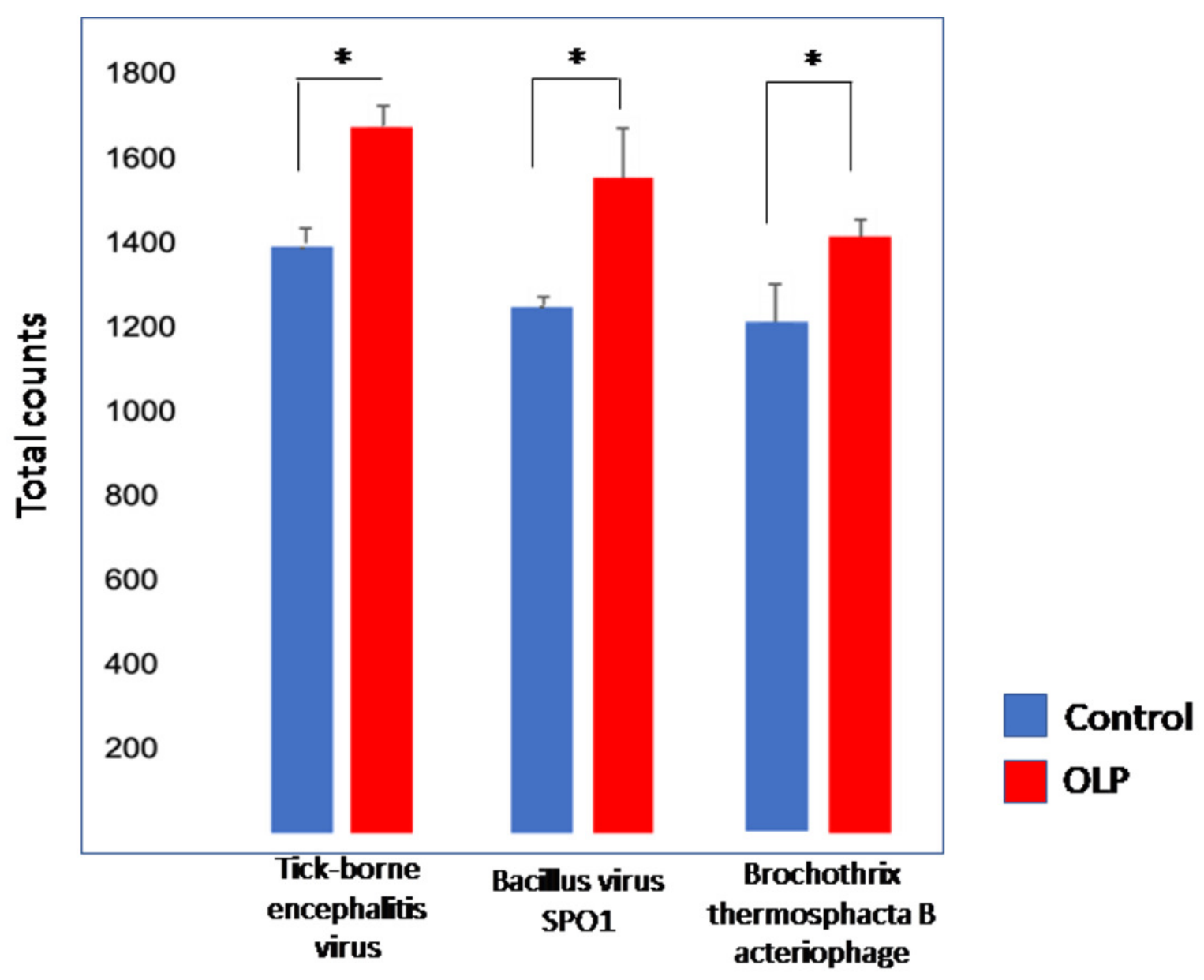

Fig 5. Three viral species are significantly different between OLP patients and healthy controls. P values are $0.0012,0.0074$, and 0.036 respectively from left to right, error bars represent s.e.m. Virus counts for the majority of species identified was higher in OLP patients when compared to that of controls. 
Table 1. Clinicopathologic and demographic features of the study population cases and controls.

\begin{tabular}{|c|c|c|c|c|c|}
\hline Cases & Age & Sex & Clinical oral diagnosis & Comorbidities & $\begin{array}{l}\text { OLP } \\
\text { Treatment }\end{array}$ \\
\hline 1 & 61 & $\mathrm{~F}$ & $\begin{array}{l}\text { OLP (reticular) } \\
\text { buccal mucosa bilateral and } \\
\text { gingiva generalized }\end{array}$ & None & $\begin{array}{l}\text { Dexamethasone } \\
\text { oral elixir } \\
0.5 \mathrm{mg} / \mathrm{mL} \text { rinse } \\
\text { and spit tid }\end{array}$ \\
\hline 2 & 76 & $\mathrm{M}$ & $\begin{array}{l}\text { OLP (erosive) } \\
\text { buccal mucosa bilateral and } \\
\text { gingiva generalized }\end{array}$ & Hypertension & $\begin{array}{l}\text { Clobetasol gel } \\
0.05 \% \text { for } \\
\text { topical use tid }\end{array}$ \\
\hline 3 & 62 & $\mathrm{~F}$ & $\begin{array}{l}\text { OLP (reticular) } \\
\text { buccal mucosa bilateral and } \\
\text { gingival generalized }\end{array}$ & $\begin{array}{l}\text { Hearing } \\
\text { impairment }\end{array}$ & $\begin{array}{l}\text { Fluocinonide } \\
\text { gel } 0.05 \% \text { for } \\
\text { topical use tid }\end{array}$ \\
\hline 4 & 63 & $\mathrm{~F}$ & $\begin{array}{l}\text { OLP (erosive and reticular) } \\
\text { buccal mucosa bilateral and } \\
\text { gingiva generalized }\end{array}$ & $\begin{array}{l}\text { Hypertension, } \\
\text { angina }\end{array}$ & $\begin{array}{l}\text { Fluocinonide } \\
\text { gel } 0.05 \% \text { for } \\
\text { topical use tid \& } \\
\text { dexamethasone } \\
\text { as in case } 1\end{array}$ \\
\hline 5 & 61 & F & $\begin{array}{l}\text { OLP (reticular) buccal } \\
\text { mucosa bilateral }\end{array}$ & $\begin{array}{l}\text { Mitral valve } \\
\text { prolapse, anemia }\end{array}$ & $\begin{array}{l}\text { Dexamethasone } \\
\text { as in case } 1\end{array}$ \\
\hline 6 & 63 & $\mathrm{~F}$ & $\begin{array}{l}\text { OLP (erosive and reticular) } \\
\text { buccal mucosa bilateral and } \\
\text { tongue }\end{array}$ & $\begin{array}{l}\text { Hypothyroidism, } \\
\text { depression }\end{array}$ & $\begin{array}{l}\text { Dexamethasone } \\
\text { as in case } 1\end{array}$ \\
\hline 7 & 59 & $\mathrm{~F}$ & $\begin{array}{l}\text { OLP (erosive and reticular) } \\
\text { buccal mucosa bilateral and } \\
\text { gingiva generalized }\end{array}$ & Anxiety & $\begin{array}{l}\text { Dexamethasone } \\
\text { as in case } 1\end{array}$ \\
\hline 8 & 72 & $\mathrm{~F}$ & $\begin{array}{l}\text { OLP (erosive and reticular) } \\
\text { buccal mucosa bilateral }\end{array}$ & $\begin{array}{l}\text { Fibromyalgia, } \\
\text { osteoarthritis, } \\
\text { hypertension, } \\
\text { hypothyroidism }\end{array}$ & $\begin{array}{l}\text { Dexamethasone } \\
\text { as in case } 1\end{array}$ \\
\hline 9 & 78 & $\mathrm{~F}$ & $\begin{array}{l}\text { OLP (reticular) buccal } \\
\text { mucosa bilateral and tongue }\end{array}$ & $\begin{array}{l}\text { Hypertension, } \\
\text { DMII }\end{array}$ & None \\
\hline 10 & 79 & $\mathrm{~F}$ & $\begin{array}{l}\text { OLP (reticular) } \\
\text { buccal mucosa bilateral }\end{array}$ & $\begin{array}{l}\text { Hypothyroidism, } \\
\text { osteoporosis }\end{array}$ & $\begin{array}{l}\text { Dexamethasone } \\
\text { as in case } 1\end{array}$ \\
\hline \multicolumn{6}{|c|}{ Controls } \\
\hline 1 & 51 & $\mathrm{~F}$ & Simple bone cyst & None & N/A \\
\hline 2 & 69 & $\mathrm{~F}$ & Fractured dental filling & Hypertension & N/A \\
\hline 3 & 72 & $\mathrm{~F}$ & Psychogenic bruxism & None & N/A \\
\hline 4 & 59 & $\mathrm{M}$ & Dental crown fracture & Hypertension & N/A \\
\hline 5 & 57 & $\mathrm{M}$ & None & None & N/A \\
\hline
\end{tabular}

